\title{
Silicon Carbide Microstrip Radiation Detectors
}

\author{
Donatella Puglisi $1,2, *$ (D) and Giuseppe Bertuccio ${ }^{1,3}$ \\ 1 Department of Electronics, Information and Bioengineering, Politecnico di Milano, Campus Como, \\ 22100 Como, Italy; giuseppe.bertuccio@polimi.it \\ 2 Department of Physics, Chemistry and Biology, Sensor and Actuator Systems, Linköping University, \\ 58183 Linköping, Sweden \\ 3 Italian National Institute of Nuclear Physics (INFN), Section Milano, 20133 Milan, Italy \\ * Correspondence: donatella.puglisi@liu.se; Tel.: +46-13-28-1273
}

Received: 17 July 2019; Accepted: 27 November 2019; Published: 30 November 2019

\begin{abstract}
Compared with the most commonly used silicon and germanium, which need to work at cryogenic or low temperatures to decrease their noise levels, wide-bandgap compound semiconductors such as silicon carbide allow the operation of radiation detectors at room temperature, with high performance, and without the use of any bulky and expensive cooling equipment. In this work, we investigated the electrical and spectroscopic performance of an innovative position-sensitive semiconductor radiation detector in epitaxial $4 \mathrm{H}-\mathrm{SiC}$. The full depletion of the epitaxial layer $(124 \mu \mathrm{m}$, $5.2 \times 10^{13} \mathrm{~cm}^{-3}$ ) was reached by biasing the detector up to $600 \mathrm{~V}$. For comparison, two different microstrip detectors were fully characterized from $-20^{\circ} \mathrm{C}$ to $+107^{\circ} \mathrm{C}$. The obtained results show that our prototype detector is suitable for high resolution $\mathrm{X}$-ray spectroscopy with imaging capability in a wide range of operating temperatures.
\end{abstract}

Keywords: silicon carbide; semiconductor radiation detector; microstrip detector

\section{Introduction}

The concept of using compound semiconductors as radiation detectors was introduced in 1945 by Van Heerden [1,2], who was the first to be able to detect alpha and gamma rays with solid-state radiation counters. His pioneering results gave rise to a new class of radiation detectors, which is now commonly known as semiconductor detectors. Compared to gas detectors, semiconductor detectors require much lower average energies for the creation of electron-hole pairs ( $30 \mathrm{eV}$ for gas [3], $3.7 \mathrm{eV}$ for $\mathrm{Si}$ [4], $7.8 \mathrm{eV}$ for 4H-SiC [5]), which bring higher energy resolution in radiation spectroscopy [6,7]. Since the 1960s, the most commonly used semiconductor materials have been high-purity silicon (Si) and germanium $(\mathrm{Ge})$, the main limitation of which is that they must operate at liquid nitrogen temperature. Since the 1990s, intense research activity has been carried out on other semiconductors for manufacturing detectors able to operate at room temperature, such as gallium arsenide (GaAs), cadmium telluride (CdTe), and cadmium zinc telluride (CdZnTe) [8-12]. In the last two decades, silicon carbide $(\mathrm{SiC})$ has obtained increasing interest in the field of radiation detectors due to the achievement of a high purity level in the crystal structure and considerable thickness $(>100 \mu \mathrm{m})$ in the epitaxial layer. This finally achieved recognition for semiconductor detectors as a real alternative to Si-based radiation detectors, which present possibilities but also limitations at and above room temperature, as well as in high-radiation environments $[13,14]$. There are certain properties that make $\mathrm{SiC}$ especially suitable for the realization of ionizing radiation detectors. Thanks to the wide energy bandgap of the polytype $4 \mathrm{H}-\mathrm{SiC}(3.26 \mathrm{eV})$, which is three times higher than that of $\mathrm{Si}(1.12 \mathrm{eV})$, electronic devices fabricated in such material can operate at extremely high temperatures without suffering from negative effects, due to thermally generated charge carriers [15]. Silicon carbide radiation detectors benefit from this property because the wide energy bandgap allows the achievement of very low leakage currents, i.e., 
very low noise levels, even at the high electric fields applied during their operation. Moreover, the high thermal conductivity of $4 \mathrm{H}-\mathrm{SiC}\left(3.8 \mathrm{~W} / \mathrm{cm}^{\circ} \mathrm{C}\right)$ enables $\mathrm{SiC}$ devices to dissipate large amounts of excess generated heat, which would cause a temperature increase, responsible for degradation of the device's performance. High thermal conductivity is useful for increasing the radiation hardness of the detector, as well as for controlling the operating temperature when the front-end electronics are close to, or in contact with, the detector [16]. Furthermore, $\mathrm{SiC}$ can withstand an internal electric field over eight to ten times greater than $\mathrm{GaAs}$ or $\mathrm{Si}(2 \mathrm{MV} / \mathrm{cm}$ for $4 \mathrm{H}-\mathrm{SiC}$ vs. $0.4 \mathrm{MV} / \mathrm{cm}$ for GaAs or $0.3 \mathrm{MV} / \mathrm{cm}$ for $\mathrm{Si}$ ) without undergoing avalanche breakdown. This property enables the fabrication of very high-voltage devices [17]. In the case of X-ray detection and spectroscopy, the high breakdown field of $4 \mathrm{H}-\mathrm{SiC}$ allows, in principle, the detector to work always in the regime of saturated-electron and hole-drift velocities, independently of the detector's active region width. When this operation condition is coupled with epitaxial material of high crystalline quality, a full and fast charge collection can be expected [16], as well as a high sensitivity, as already demonstrated [18]. Such properties allow SiC-based devices to be operated without any costly, bulky, and power-consuming cooling systems, as in the case of Si- or Ge-based devices, while maintaining an excellent signal-to-noise ratio over a wide range of temperatures. This leads to notable advantages in terms of the lower cost, more compact size, lighter weight, lower power consumption, and higher performance of SiC detectors. Further explanation of the electrical properties of $\mathrm{SiC}$ in connection with the ionizing detector performance benefits can be found in [16].

Microstrip detectors find application where the position of the radiation interaction is necessary information for the physical process to be studied. The advantage of using microstrips with respect to other position-sensitive detectors, such as pixel detectors, is a lower number of readout channels. Several microstrip detectors have been developed in Si for high-energy physics, or in Ge, CdTe and GaAs for X-ray spectroscopy [19-22]. In this work, we investigated the electrical and spectroscopic performance of two innovative position-sensitive radiation detectors in epitaxial $4 \mathrm{H}-\mathrm{SiC}$, using microstrip geometry. The detectors were characterized in detail at different temperatures and applied bias voltages. The obtained results are presented and discussed in the following sections.

\section{Materials and Methods}

Two different designs of silicon carbide microstrip detectors have been realized on top of two-inch high-purity epitaxial 4H-SiC wafer produced by LPE Epitaxial Technology Center [23]. Each detector consists of 32 strips with a length of $2 \mathrm{~mm}$, a width of either $25 \mu \mathrm{m}$ (SM1) or $50 \mu \mathrm{m}$ (SM3), and a pitch of either $55 \mu \mathrm{m}$ (SM1) or $100 \mu \mathrm{m}$ (SM3) — see Figure 1. Each of these strips can be read out independently by a front-end electronics channel, and therefore behaves as a separate detector. A cross-sectional view of the $4 \mathrm{H}-\mathrm{SiC}$ microstrip structure is shown in Figure 2. The SiC epitaxial layer, which is the active region of the detector, has a maximum thickness of $124 \mu \mathrm{m}$, as experimentally measured (Figure 3).

The application of a reverse bias at the common back electrode (ohmic contact) creates a depletion region, $x_{d}$, depending on the applied bias, $V_{R}$, and the residual doping (donor) concentration, $\mathrm{N}_{\mathrm{D}}$, within the material, according to

$$
x_{d}=\sqrt{\frac{2 \varepsilon_{0} \varepsilon_{r}}{q N_{D}}\left(\psi_{b i}-V_{R}-\frac{k T}{q}\right)}
$$

where $\psi_{b i}$ is the built-in potential and the term $\frac{k T}{q}$ arises from the contribution of the majority-carrier distribution tail [24]. 


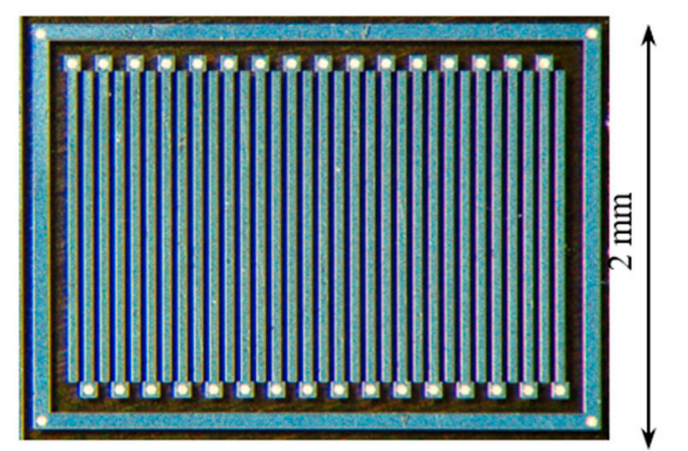

$3.35 \mathrm{~mm}$

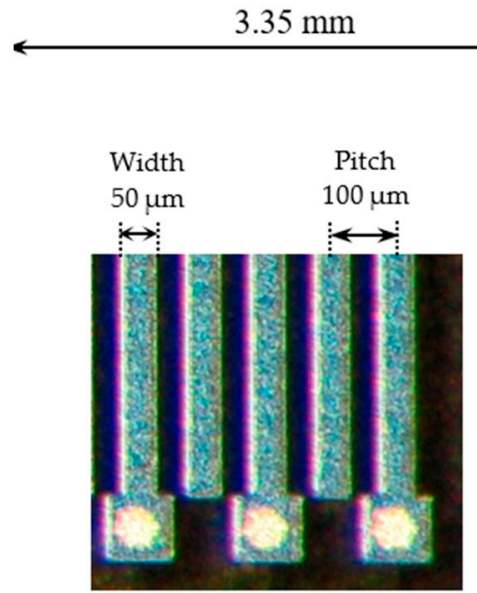

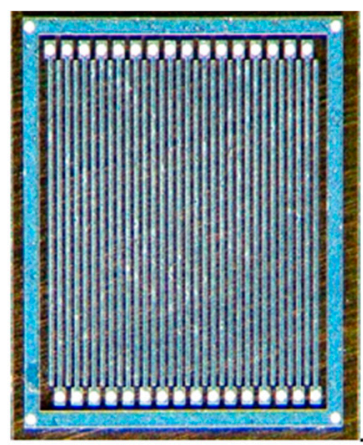

$1.84 \mathrm{~mm}$

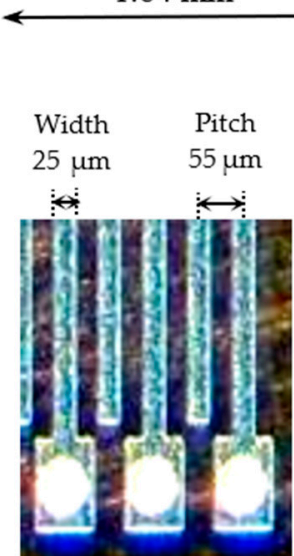

Figure 1. Photographs of the two microstrip detectors used in this work, together with a detail of their peripheral regions with bonding pads.

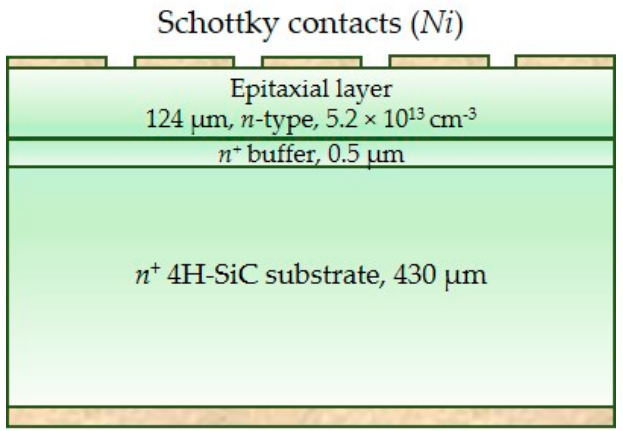

Ohmic contact $(\mathrm{Ni} / \mathrm{Ti} / \mathrm{Pt} / \mathrm{Au})$

Figure 2. Cross-sectional view of the $4 \mathrm{H}-\mathrm{SiC}$ microstrip structure.

The residual doping concentration depends on the homogeneity of the epitaxial layer. The donor concentration profile, $N_{D}(x)$, was determined as a function of the depleted layer width from capacitance-voltage measurements, as described in Section 3.

\section{Results}

\subsection{Electrical Characterization}

\subsubsection{Capacitance-Voltage Characterization}

Capacitance-voltage $(\mathrm{C}-\mathrm{V})$ measurements were carried out up to $600 \mathrm{~V}$ at $25{ }^{\circ} \mathrm{C}$, in order to determine the donor-concentration profile of the epitaxial layer (Figure 3a). The detector was placed in a test fixture Agilent 16065A connected to an Agilent 4284A Precision LCR Meter (Santa Clara, CA, USA). A Keithley 2410 voltage source (Cleveland, OH, USA), operating in the four-wire connection mode, 
was used to bias the device and measure the applied voltage. The measurement was performed with a $100 \mathrm{mV}$ AC signal at $100 \mathrm{kHz}$. The donor-concentration profile as a function of the depleted layer width was determined from the slope of a $1 / C^{2}-V$ curve, according to [24], see Figure 3a. Please note that the $\mathrm{C}-\mathrm{V}$ measurements were performed using a $4 \mathrm{H}-\mathrm{SiC}$ Schottky diode with area $A=5 \mathrm{~mm}^{2}$, produced from the same wafer. A full depletion of $124 \mu \mathrm{m}$ was reached, polarizing the detector up to $600 \mathrm{~V}$ (Figure 3b). A mean value of $\left\langle\mathrm{N}_{\mathrm{D}}>=(5.20 \pm 0.06) \times 10^{13} \mathrm{~cm}^{-3}\right.$ was determined (Figure 4).

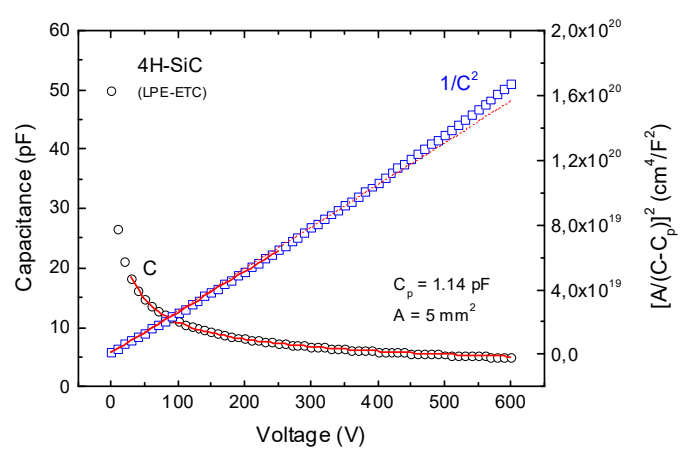

(a)

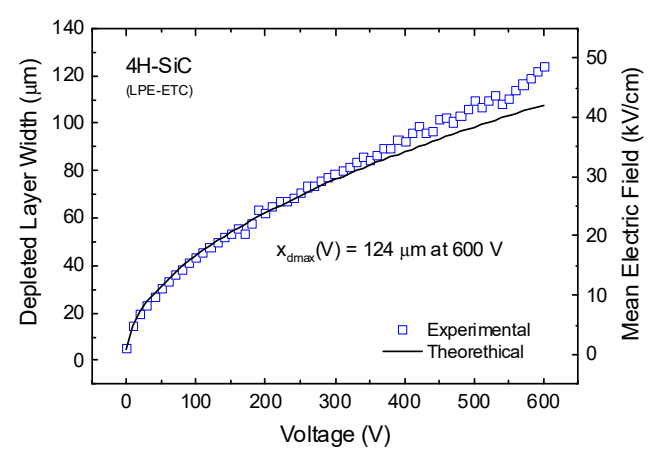

(b)

Figure 3. (a) Capacitance-voltage $(C-V)$ and $1 / C^{2}-V$ per unit area characteristics. From the fit curve, the mean value of the donor concentration is expected to be $(5.56 \pm 0.05) \times 10^{13} \mathrm{~cm}^{-3}$; (b) depleted layer and mean electric field as a function of applied voltage, as derived from $\mathrm{C}-\mathrm{V}$ measurements. The theoretical result is obtained using $5.56 \times 10^{13} \mathrm{~cm}^{-3}$ as the mean value of the doping concentration.

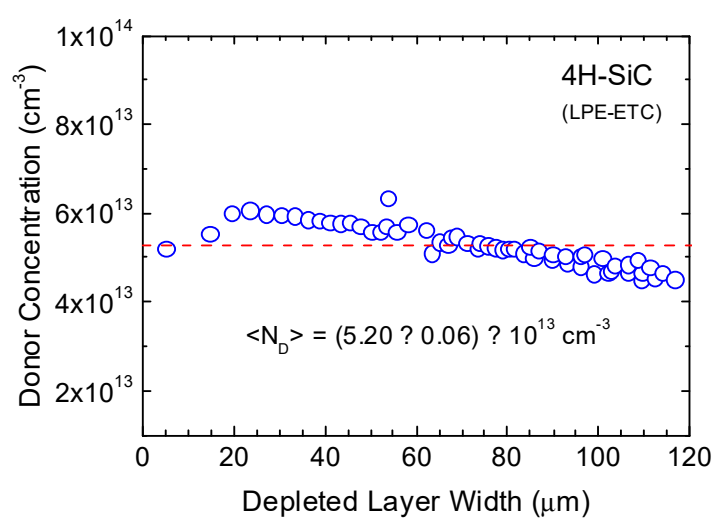

Figure 4. Donor concentration profile as a function of the depleted layer width. The full depletion of $124 \mu \mathrm{m}$ was reached at $600 \mathrm{~V}$. A mean value of $\left\langle\mathrm{N}_{\mathrm{D}}>=5.2 \times 10^{13} \mathrm{~cm}^{-3}\right.$ was determined.

\subsubsection{Statistical Leakage-Current Distribution}

Current-voltage (I-V) measurements were carried out on each of the 32 strips of two different SiC detectors, SM1 and SM3, at room temperature (Figure 5). The two detectors were biased at $100 \mathrm{~V}$ and $200 \mathrm{~V}$ from the back ohmic contact using a Keithley 2410 source meter, whereas the current of each strip was measured connecting a Keithley 6430 electrometer to the front, rectifying the Schottky contact. The guard electrode surrounding the microstrips was kept to ground to collect the parasitic current generated at the device's chip edges. Figure 5 shows the current and current density values for each of the 32 strips of the two different microstrip detectors as measured at $25^{\circ} \mathrm{C}$ and $200 \mathrm{~V}$. Such bias voltage generates an inner electric field of about $30 \mathrm{kV} / \mathrm{cm}$. Ultra-low current mean values of $2.2 \mathrm{fA}$ and 7.6 fA were measured for the two microstrips under test, corresponding to current densities of $4.4 \mathrm{pA} / \mathrm{cm}^{2}$ and $15.2 \mathrm{pA} / \mathrm{cm}^{2}$. 


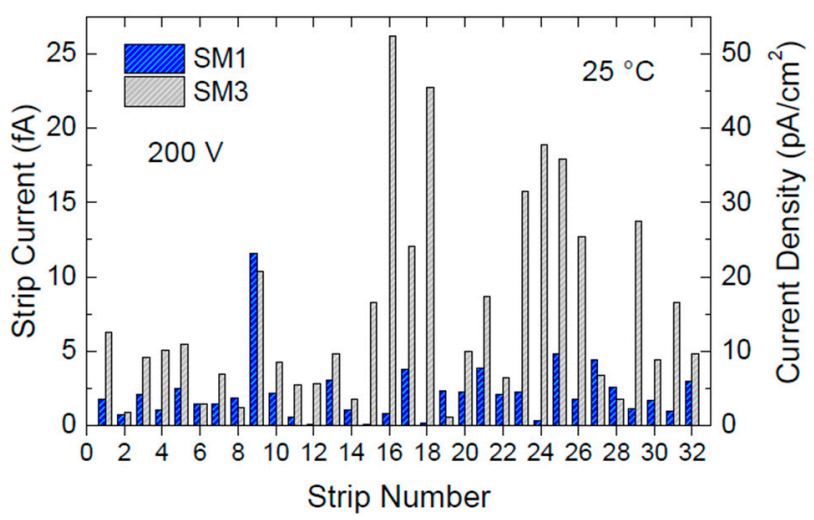

Figure 5. Current and current density measured at $25^{\circ} \mathrm{C}$ and $200 \mathrm{~V}$ on the 32 strips of the two microstrip detectors, SM1 and SM3. Current values of few fA (current densities of low $\mathrm{pA} / \mathrm{cm}^{2}$ ) were measured on all strips.

\subsubsection{Temperature Dependence}

The temperature dependence of the strip current as a function of reverse-bias voltage is shown in Figure 6. From now on, only results obtained with the detector SM1 are presented. In order to perform this measurement, the device was attached to a Teflon circuit board using a silver conductive glue. Electrical contacts were established using $25 \mu \mathrm{m}$ gold wire-bonding connections. Measurements were acquired, biasing up to $200 \mathrm{~V}$ the back contact with the Keithley 2410 source meter and reading the currents from the Keithley 6430 electrometer. Tests were carried out inside an environmental chamber, setting the temperature at $27^{\circ} \mathrm{C}, 47^{\circ} \mathrm{C}, 67^{\circ} \mathrm{C}, 87^{\circ} \mathrm{C}$, and $107^{\circ} \mathrm{C}$, and monitoring it by means of a thermocouple placed near to the device. During each measurement, the temperature changes were monitored within $\pm 0.1^{\circ} \mathrm{C}$. The current density was calculated considering a strip active area of $5 \times 10^{-4} \mathrm{~cm}^{-2}$.

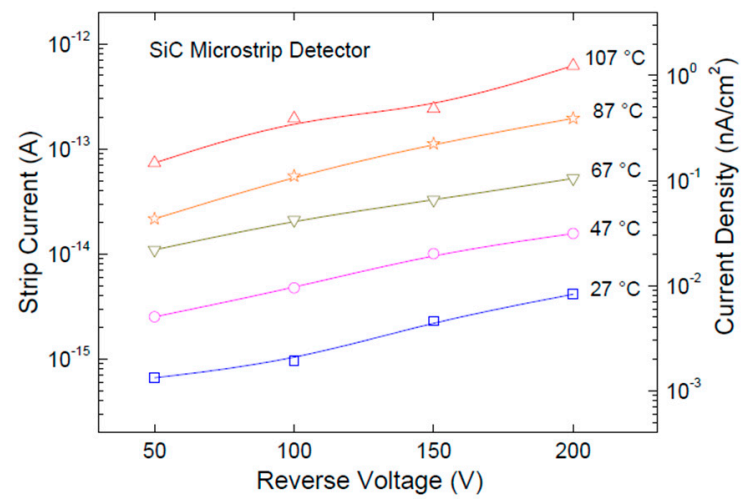

Figure 6. Current and current density dependence from temperature in the range 27 to $107^{\circ} \mathrm{C}$.

Such a thermally activated process is described by the Arrhenius plot that, according to the emission theory, is expressed by

$$
I=I_{0} \cdot \exp \left[\left(-\frac{E_{A}}{k T}\right) \cdot\left(1-\frac{T}{T_{0}}\right)\right]
$$

where $I_{0}$ is the saturation current, $T_{0}$ is the room temperature, and $E_{\mathrm{A}}$ is the activation energy $[5,25]$.

Figure 7 shows the Arrhenius plots of the leakage current as a function of 1000/T at four different reverse voltages, i.e., $50 \mathrm{~V}, 100 \mathrm{~V}, 150 \mathrm{~V}$, and $200 \mathrm{~V}$. The activation energy is given by the slope of linear fit of data. Values from $0.57 \mathrm{eV}$ to $0.65 \mathrm{eV}$ were calculated in the voltage range $50 \mathrm{~V}$ to $200 \mathrm{~V}$. According to the literature, these values refer to major deep levels ( $Z_{1 / 2}$ center) within the bandgap [26-28]. 


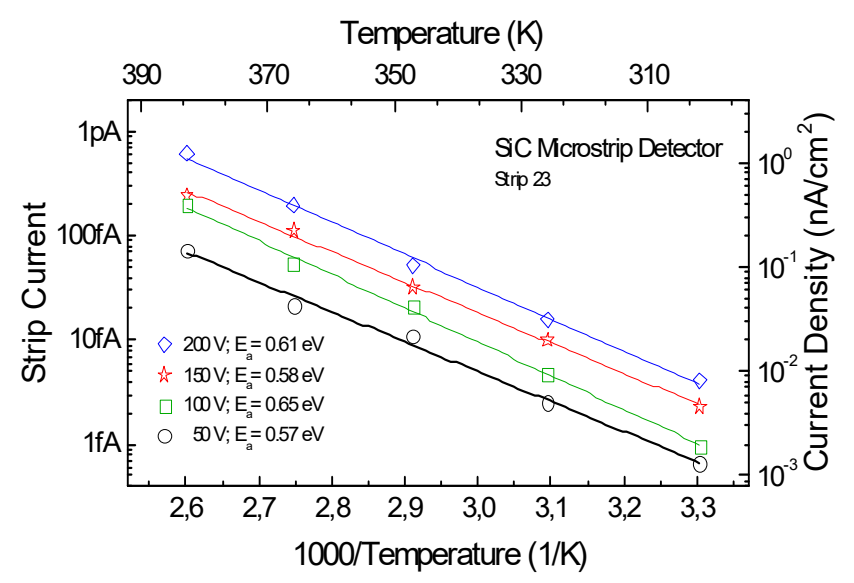

Figure 7. Arrhenius plots of the leakage current (and current density) versus the reverse of temperature at four different voltages. The activation energy values are from $0.57 \mathrm{eV}$ to $0.65 \mathrm{eV}$ in the voltage range 50 to $200 \mathrm{~V}$.

\subsubsection{Interstrip Resistance Measurements}

Current-voltage measurements shown in previous sections refer to the characterization of single strips, considering that the measured current arrived only from the back contact of the device, and possible latent currents from adjacent strips were negligible. In order to determine the bias limit condition so that two adjacent strips can be considered isolated, we measured the interstrip resistance.

Interstrip resistance measurements were carried out by measuring the current between two consecutive strips, keeping the back contact at $100 \mathrm{~V}$ and the guard at $0 \mathrm{~V}$. One of the two strips (microstrip 2 in Figure 8) is biased from $-5 \mathrm{~V}$ to $+5 \mathrm{~V}$ while the current of the other strip (microstrip 1 in Figure 8), kept at $0 \mathrm{~V}$, is measured by an electrometer. We repeated the test on three couples of strips. The negative slope shown in Figure 8 is due to the application of the bias voltage to microstrip 2 while measuring the current at microstrip 1 . The mean value of resistance between two adjacent strips of SM1 resulted in $5.3 \mathrm{~T} \Omega$.

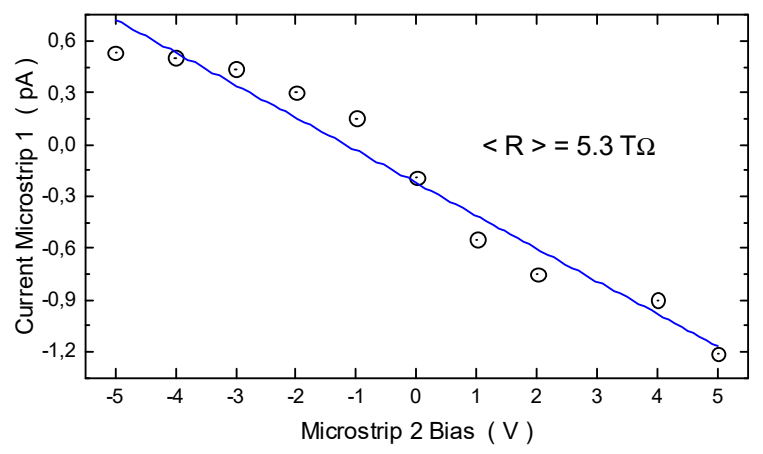

Figure 8. Mean value of resistance between two adjacent strips.

\subsection{X-Ray Spectroscopy}

\subsubsection{Room Temperature}

The detector was irradiated with a $397 \mathrm{kBq}{ }^{241} \mathrm{Am}$ source placed at a few $\mathrm{cm}$ from the detector surface. Figure 9a shows a ${ }^{241} \mathrm{Am}$ spectrum acquired using a SiC microstrip detector at $21^{\circ} \mathrm{C}$. The spectrum was acquired at $200 \mathrm{~V}$ reverse-bias condition using $12.8 \mu$ s peaking time in the triangular signal processing. The pulser line width is $214 \mathrm{eV}$ full width at half maximum (FWHM) corresponding to an equivalent noise charge of 11.6 electrons root mean square (rms). Figure $9 \mathrm{~b}$ shows a detail of the same measurement up to $28 \mathrm{keV}$. Several X-ray lines from $\mathrm{Mn}, \mathrm{Cu}, \mathrm{Np}$, and $\mathrm{Ag}$ can be clearly distinguished with a very good resolution, i.e., enough to separate the $K$ and $L$ lines of neighboring 
elements. Conventionally, the energy resolution, that is the FWHM, is specified for the Mn K $\alpha$ peak at $5.9 \mathrm{keV}$, which is $213 \mathrm{eV}$ for our $\mathrm{SiC}$ microstrip detector at room temperature (Figure 9). It is notable that $\mathrm{Si}(\mathrm{Li})$ and silicon drift detectors can achieve 130-150 eV FWHM, and Ge detectors can even achieve $115 \mathrm{eV}$ FWHM for the Mn K $\alpha$ peak at $5.9 \mathrm{keV}$, but with liquid-nitrogen cooling [29].

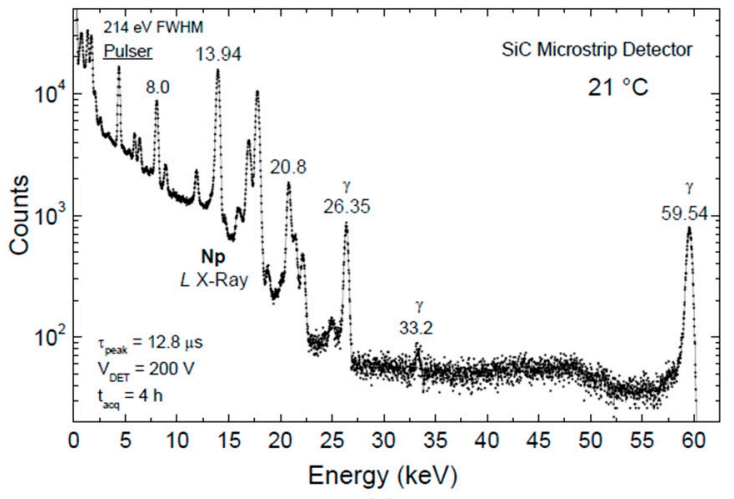

(a)

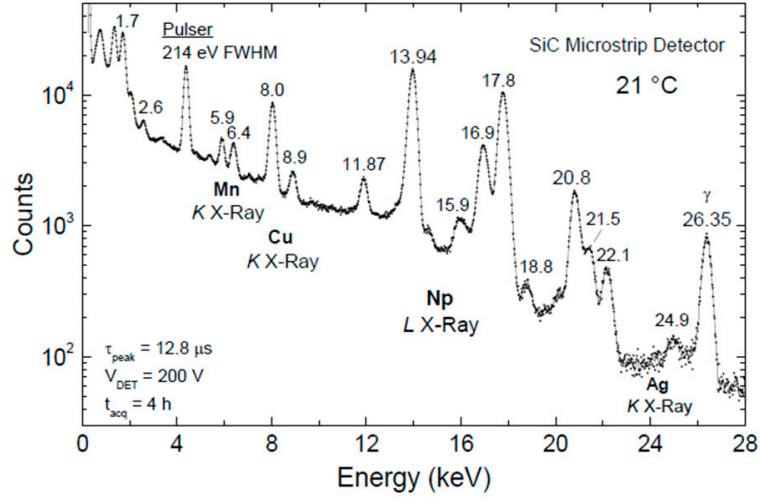

(b)

Figure 9. (a) X-ray spectrum from a ${ }^{241} \mathrm{Am}$ source acquired at $21^{\circ} \mathrm{C}$ using the $\mathrm{SiC}$ microstrip detector SM1 and an ultra-low noise front-end (PRE5 no. 3); (b) detailed X-ray spectroscopy in the energy range 0 to $28 \mathrm{keV}$.

The analysis of linearity calculated on seven well-resolved peak lines at 8.0, 11.87, 13.94, 17.8, 20.8, 26.35 and $59.54 \mathrm{keV}$ is shown in Figure 10. The percentage error from linearity is below $\pm 0.05 \%$.

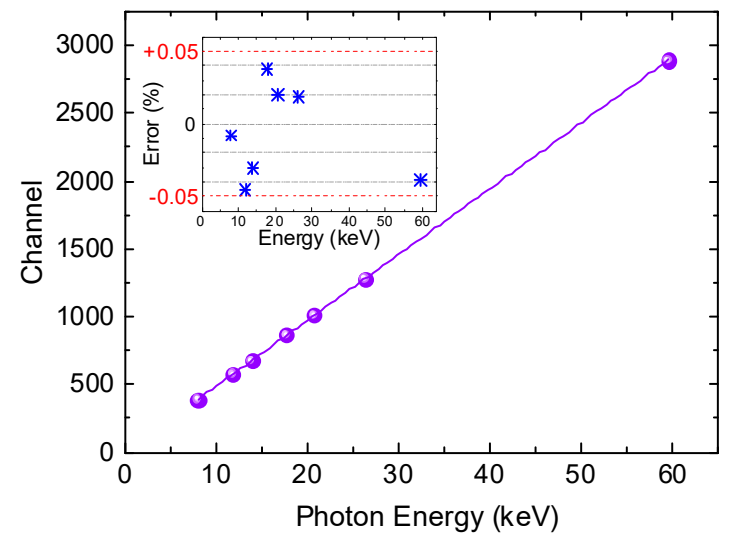

Figure 10. Analysis of linearity calculated on seven well-resolved peak lines, as shown in Figure 9. The percentage error from linearity is below $\pm 0.05 \%$.

\subsubsection{Dependence of X-Ray Response on Detector Bias}

The dependence of $\mathrm{X}$-ray response on detector voltage was explored by biasing the detector from $10 \mathrm{~V}$ to $200 \mathrm{~V}$ at $25{ }^{\circ} \mathrm{C}$ and using a peaking time of $12.8 \mu \mathrm{s}$. A comparison between two spectra acquired at $10 \mathrm{~V}$ (bottom, blue) and $200 \mathrm{~V}$ (top, red) is shown in Figure 11. The pulser centroid is stable at both $10 \mathrm{~V}$ and $200 \mathrm{~V}$. The peak at $13.94 \mathrm{keV}$ shows a small shift of six channels (from 669 at $10 \mathrm{~V}$ to 675 at $200 \mathrm{~V}$ ) which corresponds to $124 \mathrm{eV}$ (Figure 12). The two peaks, as compared in Figure 12a, show a Gaussian symmetry without any tails. This experiment shows that SiC detectors can be operated in a wide range of bias voltages without suffering from a strong performance loss. Figure $12 \mathrm{~b}$ shows the detection rate of the $13.94 \mathrm{keV}$ photon peak at six different applied reverse-bias voltages, $V_{b}$. As expected, the photon rate increases with the square root of $V_{b}$ due to the widening of the active region (depletion layer). 


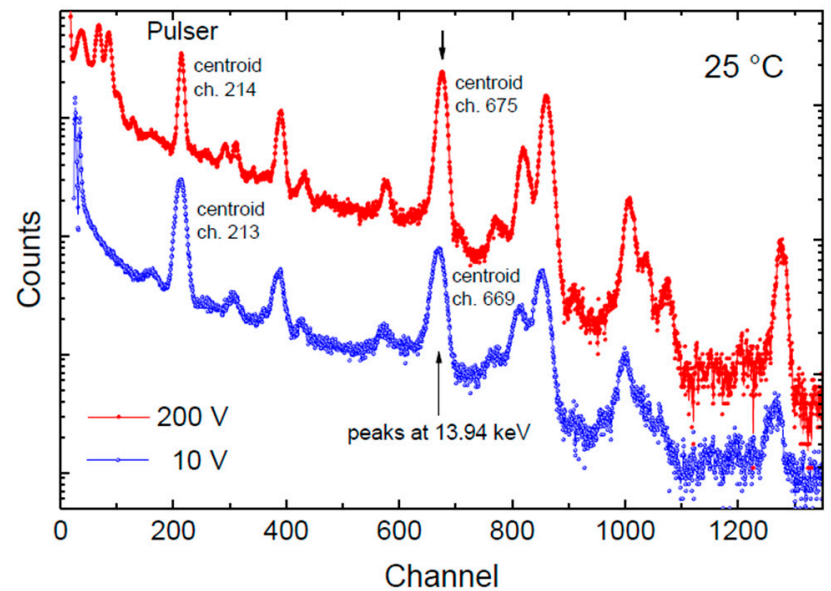

Figure 11. X-ray spectra from a ${ }^{241} \mathrm{Am}$ source acquired at $25^{\circ} \mathrm{C}$ and at $10 \mathrm{~V}$ (bottom) and $200 \mathrm{~V}$ (top).

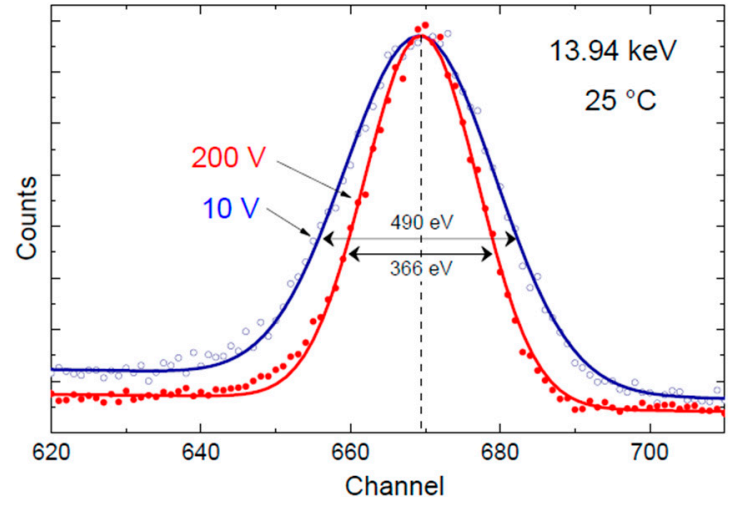

(a)

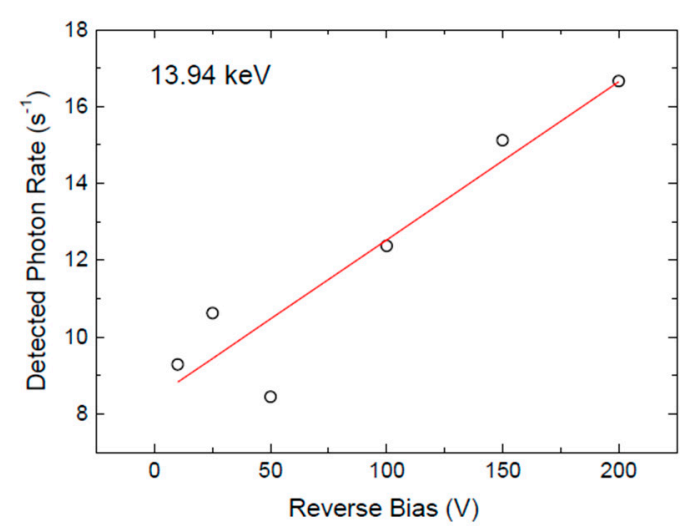

(b)

Figure 12. (a) Comparison between the two peaks at $13.94 \mathrm{eV}$ obtained at $10 \mathrm{~V}$ and $200 \mathrm{~V}$ of applied voltage. The Gaussian symmetry without tails can be noticed; (b) Detected $13.94 \mathrm{keV}$ photon rate as a function of the applied reverse bias.

\subsubsection{High Statistics and Temperature Dependence}

Figure 13 shows the results obtained by acquiring an $\mathrm{X}-\gamma$-ray spectrum for $10 \mathrm{~h}$ at $80 \mathrm{~V}$ reverse-bias condition, and maintaining the thermostatic chamber at a constant temperature of $30{ }^{\circ} \mathrm{C}$. Figure $13 \mathrm{a}$ compares spectra acquired after almost $2 \mathrm{~h}$ and after $10 \mathrm{~h}$. The very small broadening of the pulser and emission lines should be noted, which demonstrates very good stability of the detector response to $\mathrm{X}$-ray exposure. The analysis of linearity on $K \mathrm{Cu}$ and $L \mathrm{~Np}$ X-ray monoenergetic lines shows a very small linearity error within $\pm 0.04 \%$ after $10 \mathrm{~h}$ of acquisition (Figure $13 \mathrm{~b}$ ).

Figure 14 shows a comparison between $\mathrm{X}$-ray spectra acquired at three different temperatures, i.e., $-20^{\circ} \mathrm{C},+30^{\circ} \mathrm{C}$, and $+80^{\circ} \mathrm{C}$. As expected, the width of pulser and emission lines increased by increasing the operating temperature: the FWHM of the pulser changed from $205 \mathrm{eV}$ at $-20{ }^{\circ} \mathrm{C}$, to $215 \mathrm{eV}$ at $+30{ }^{\circ} \mathrm{C}$, and $249 \mathrm{eV}$ at $+80^{\circ} \mathrm{C}$. It is worth noticing the small broadening of the lines at $+80^{\circ} \mathrm{C}$, which demonstrates the suitability of our microstrip detector to be used at high temperatures with very good stability of the detector response. 


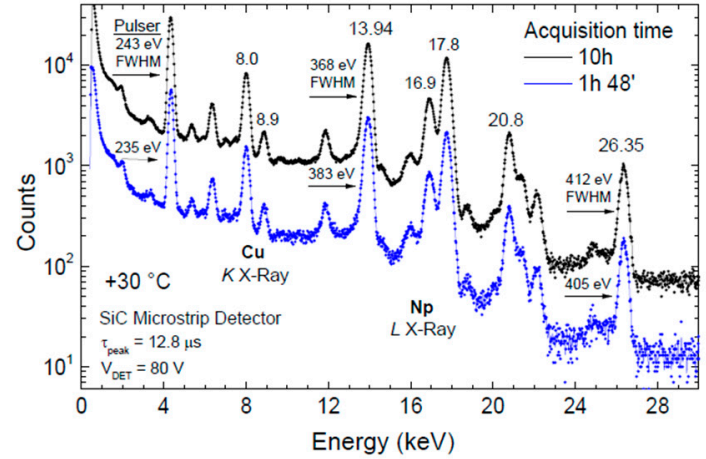

(a)

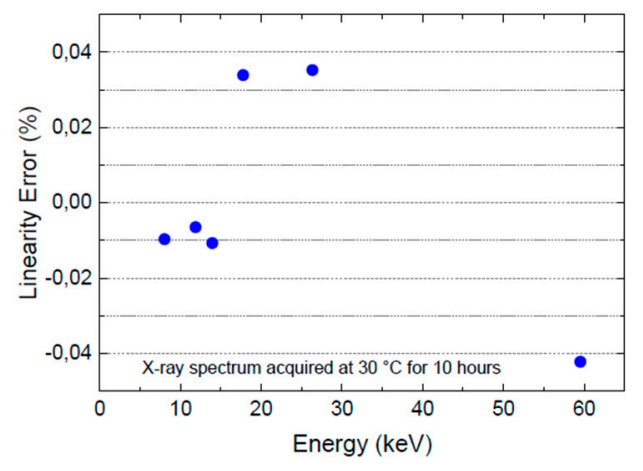

(b)

Figure 13. (a) X-ray spectra from ${ }^{241} \mathrm{Am}$ source after almost 2 and $10 \mathrm{~h}$ of acquisition at $30{ }^{\circ} \mathrm{C}$ in a thermostatic chamber. The very small broadening of pulser and emission lines demonstrates very good stability of the detector response to X-ray exposure; (b) linearity error after $10 \mathrm{~h}$ of acquisition based on $K \mathrm{Cu}$ and $L \mathrm{~Np}$ X-ray monoenergetic lines.

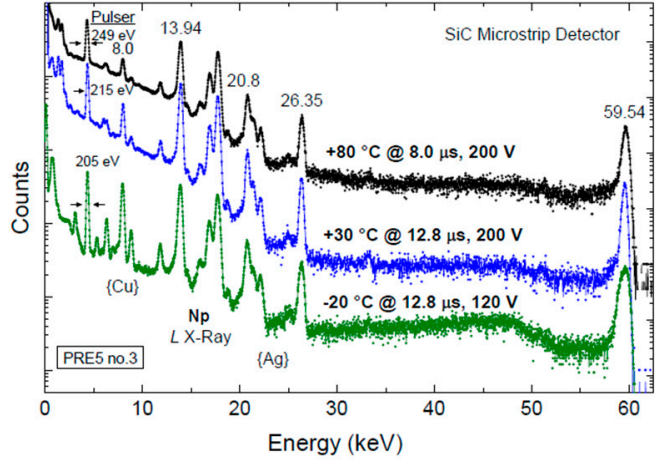

(a)

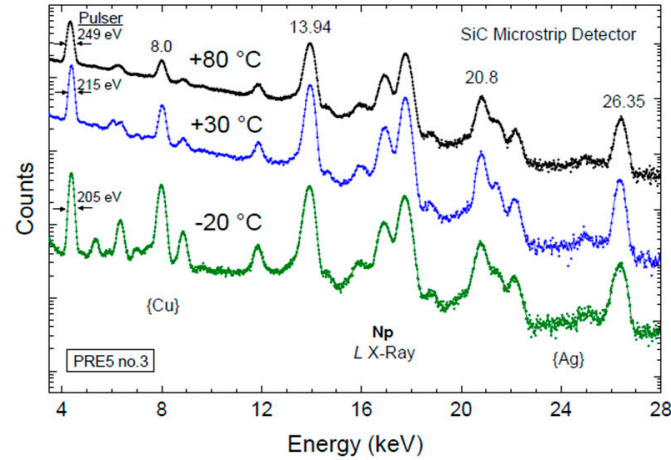

(b)

Figure 14. (a) Comparison between three $\mathrm{X}$-ray spectra acquired at $-20{ }^{\circ} \mathrm{C},+30{ }^{\circ} \mathrm{C}$, and $+80{ }^{\circ} \mathrm{C}$ in the range $0-60 \mathrm{keV}$; (b) Detail of the X-ray spectra in the range $4-28 \mathrm{keV}$. Note a small broadening of the pulser line by increasing the operating temperature.

\section{Discussion}

Two SiC-based microstrip detectors were fully characterized in a wide temperature range by means of electrical and spectroscopic measurements. A high stability of the detector response as a function of operating temperature as well as of applied voltage was widely demonstrated.

The very low leakage currents (current densities) from about $2 \mathrm{fA}\left(4 \mathrm{pA} / \mathrm{cm}^{2}\right)$ at $25^{\circ} \mathrm{C}$ to $620 \mathrm{fA}$ $\left(1.2 \mathrm{nA} / \mathrm{cm}^{2}\right)$ at $107^{\circ} \mathrm{C}$ are among the best values measured on $\mathrm{SiC}$ detectors, and more than one order of magnitude lower than most silicon detectors [30,31]. Since the shot noise of the leakage current is a significant noise contribution in a radiation spectroscopy system, we can say that our $\mathrm{SiC}$ detectors allow the achievement of high signal-to-noise ratios. A good isolation between adjacent strips was demonstrated by the high value of the measured interstrip resistance of $5.3 \mathrm{~T} \Omega$, confirming that possible latent currents from adjacent strips can be considered negligible.

A very good doping uniformity of the whole epitaxial layer was also demonstrated. For the first time, a full depletion of $124 \mu \mathrm{m}$ was reached, polarizing the detector at $600 \mathrm{~V}$, and a mean value of $<\mathrm{N}_{\mathrm{D}}>=5.2 \times 10^{13} \mathrm{~cm}^{-3}$ was determined. In comparison with previous studies, this result is the best observed [32].

The X-ray spectra acquired from a ${ }^{241} \mathrm{Am}$ source at different voltages, temperatures, and exposure times showed high stability and a high spectroscopic resolution under all tested experimental conditions.

Different voltages were used to verify the effect of the applied bias voltage on the device performance. The spectroscopic response of our SiC detector does not significantly depend on the bias voltage, as shown in Figure 11, where two extreme bias voltages $(10 \mathrm{~V}$ and $200 \mathrm{~V})$ were used. 
No tails in the spectral lines were observed, which means that no significant charge trapping occurred in these devices. Remarkably, no strong performance loss was observed at $10 \mathrm{~V}$, and substantially no difference was observed under operation between $80 \mathrm{~V}$ and $200 \mathrm{~V}$. The possibility of using a lower voltage without losing significant information is an advantage for those applications wherein lower power consumption is desirable. The better resolution obtained at $200 \mathrm{~V}$ is due to a lower capacitance. We avoided operating the $\mathrm{SiC}$ detector above $200 \mathrm{~V}$ to prevent the risk of possible damages due to accidental breakdown or electrostatic discharge. Also, the exposure time to the ${ }^{241} \mathrm{Am}$ source does not affect the spectroscopic performance of our $\mathrm{SiC}$ detector, as demonstrated by negligible differences in the peak resolution after almost 2 and $10 \mathrm{~h}$ of acquisition (Figure 13). This means that it is not necessary to wait for a long time before getting all the main information from the device.

Finally, it is worth noticing the high resolution and very good stability in the performance of our $\mathrm{SiC}$ microstrip detector between $-20^{\circ} \mathrm{C}$ and $+80^{\circ} \mathrm{C}$ (Figure 14), which pave the way for use in a wide range of applications that are prohibitive for other conventional semiconductor detectors.

\section{Conclusions}

Even considering an initial higher cost for the SiC material in comparison to Si or Ge, SiC-based semiconductor radiation detectors are advantageous for use in operating conditions under which conventional semiconductor detectors in Si or Ge cannot adequately perform. One overall advantage is the elimination of cryogenic or Peltier cooling systems that allows the fabrication of far more compact, more stable, lighter, and lower power radiation detector systems. This also implies, as a direct consequence, economic advantages that go beyond the mere costs for the material itself.

Our findings confirm the high quality and the good uniformity of the epitaxial layer used for manufacturing our SiC-based prototypes, as well as the suitability of such devices to be used as high resolution $\mathrm{X}$-ray detectors over a wide range of operating temperatures.

Author Contributions: Investigation, D.P. and G.B.; Supervision, G.B.; Writing - original draft, D.P. and G.B.; Writing - review \& editing, D.P.

Funding: This research was funded by the Italian National Institute of Nuclear Physics (INFN) and by the Italian Space Agency (ASI). The APC was funded by Linköping University.

Acknowledgments: All experiments were performed at the Semiconductor and Integrated Circuit Laboratory of the Department of Electronics, Information and Bioengineering, Politecnico di Milano, Como Campus, Italy. The authors would like to thank C. Lanzieri for device manufacturing process at Selex Integrated Systems (Rome), P. Ferrari for his contribution to the electrical characterization, S. Masci for the device bonding, S. Caccia and D. Macera for their collaboration for the readout electronics. The authors would like to dedicate this work to the everlasting memory of Andrea Puglisi.

Conflicts of Interest: The authors declare no conflicts of interest. The founding sponsors had no role in the design of the study; in the collection, analyses, or interpretation of data; in the writing of the manuscript, and in the decision to publish the results.

\section{References}

1. Van Heerden, P.J. The Crystal Counter: A new apparatus in nuclear physics for the investigation of $\beta$ - and $\gamma$-rays. Part, I. Physica 1950, 16, 505-516. [CrossRef]

2. Van Heerden, P.J.; Milatz, J.M.W. The Crystal Counter: A new apparatus in nuclear physics for the investigation of $\beta$ - and $\gamma$-rays. Part II. Physica 1950, 16, 517-527. [CrossRef]

3. Lerov, C.; Rancoita, P.-G. Principles of Radiation Interaction in Matter and Detection, 2nd ed.; Word Scientific: Singapore, 2009; p. 83. ISBN 978-981-4470-89-6.

4. Scholze, F.; Rabus, H.; Ulm, G. Mean energy required to produce an electron-hole pair in silicon for photons of energies between 50 and 1500 eV. J. Appl. Phys. 1998, 84, 2926-2939. [CrossRef]

5. Bertuccio, G.; Casiraghi, R. Study of silicon carbide for X-ray detection and spectroscopy. IEEE Trans. Nucl. Sci. 2003, 50, 175-185. [CrossRef] 
6. Knoll, G.N. Radiation Detection and Measurement, 4th ed.; Wiley: New York, NY, USA, 2010; ISBN 978-0-470-13148-0.

7. Lutz, G. Semiconductor Radiation Detectors: Device Physics, 2nd printing of the 1st ed.; Springer: Berlin/Heidelberg, Germany, 2007; ISBN 978-3-540-71679-2.

8. McGregor, D.S.; Hermon, H. Room-temperature compound semiconductor radiation detectors. Nucl. Instrum. Methods Phys. Res. A Accel. Spectrom. Detect. Assoc. Equip. 1997, 395, 101-124. [CrossRef]

9. Bertuccio, G. Prospect for Energy Resolving X-ray Imaging with Compound Semiconductor Pixel Detectors. Nucl. Instrum. Methods Phys. Res. A Accel. Spectrom. Detect. Assoc. Equip. 2005, 546, 232-241. [CrossRef]

10. Schlesinger, T.E.; James, R.B. (Eds.) Semiconductor for Room Temperature Nuclear Detectors Applications, Semiconductor and Semimetal Series; 1st ed.; Academic Press: San Diego, CA, USA, 1995; Volume 43, ISBN 9780080571997.

11. Owens, A.; Bavdaz, M.; Peacock, A.; Poelaert, A. High resolution x-ray spectroscopy using GaAs arrays. J. Appl. Phys. 2001, 90, 5376-5381. [CrossRef]

12. Abbene, L.; Del Sordo, S.; Caroli, E.; Gerardi, G.; Raso, G.; Caccia, S.; Bertuccio, G. Hard X-ray Response of Pixellated CdZnTe detectors. J. Appl. Phys. 2009, 105, 124508. [CrossRef]

13. Bertuccio, G.; Pullia, A. Room Temperature X-Ray Spectroscopy with a Silicon Diode Detector and an Ultra Low Noise Preamplifier. IEEE Trans. Nucl. Sci. 1994, 41, 1704-1709. [CrossRef]

14. Pullia, A.; Bertuccio, G. Resolution Limits of Silicon Detectors and Electronics for Soft X Ray Spectroscopy at non Cryogenic Temperatures. Nucl. Instrum. Methods Phys. Res. A Accel. Spectrom. Detect. Assoc. Equip. 1996, 380, 1-5. [CrossRef]

15. Bertuccio, G.; Caccia, S.; Casiraghi, R.; Lanzieri, C. Possibility of sub-electron noise with room temperature silicon carbide pixel detectors. IEEE Trans. Nucl. Sci. 2006, 53, 2421-2427. [CrossRef]

16. Nava, F.; Bertuccio, G.; Cavallini, A.; Vittone, E. Silicon carbide and its use as a radiation detector material. Meas. Sci. Technol. 2008, 19, 102001. [CrossRef]

17. Kimoto, T.; Cooper, J.A. Fundamentals of Silicon Carbide Technology, 1st ed.; IEEE Press: Piscataway, NJ, USA; John Wiley \& Sons: Hoboken, NJ, USA; Singapore Pte. Ltd.: Singapore, 2014; ISBN 978-1-118-31352-7.

18. Mandal, K.C.; Muzykov, P.G.; Terry, J.R. Highly sensitive x-ray detectors in the low-energy range on n-type 4H-SiC epitaxial layers. Appl. Phys. Lett. 2012, 101, 051111. [CrossRef]

19. Sadrozinski, H.F.-W. Silicon microstrip detectors in high luminosity application. IEEE Trans. Nucl. Sci. 1998, 45, 295-302. [CrossRef]

20. Rossi, G.; Morse, J.; Protic, D. Energy and position resolution of germanium microstrip detectors at X-ray energies from 15 to $100 \mathrm{keV}$. IEEE Trans. Nucl. Sci. 1999, 46, 765-773. [CrossRef]

21. Dusi, W.; Auricchio, N.; Brigliadori, L.; Cola, A.; Donati, A.; Landini, G.; Mengoni, D.; Perillo, E.; Siffert, P.; Ventura, G. A study of the spectroscopic performance of a CdTe microstrip detector. IEEE Trans. Nucl. Sci. 2003, 50, 1026-1030. [CrossRef]

22. Kaluza, A.; Ohms, T.; Rente, C.; Engels, R.; Reinartz, R.; Luth, H. Microstrip X-ray detector with a very high dynamic range based on LPE-GaAs. IEEE Trans. Nucl. Sci. 1998, 45, 724-727. [CrossRef]

23. LPE Epitaxial Technology, S.p.A. Available online: http://www.lpe-epi.com/ (accessed on 21 June 2019).

24. Sze, S.M.; Ng, K.K. Physics of Semiconductor Devices, 3rd ed.; John Wiley \& Sons Inc.: Hoboken, NJ, USA, 2007; pp. 85-137. ISBN 978-0-471-14323-9.

25. Schroder, D.K. Semiconductor Material and Device Characterization, 3rd ed.; John Wiley \& Sons Inc.: Hoboken, NJ, USA, 2006; p. 691. ISBN 978-0-471-73906-7.

26. Knoll, L.; Kranz, L.; Alfieri, G. Electrically active deep levels formed by thermal oxidation of n-type $4 \mathrm{H}-\mathrm{SiC}$. J. App. Phys. 2019, 125, 205302. [CrossRef]

27. Mannan, M.A.; Nguyen, K.V.; Pak, R.O.; Oner, C.; Mandal, K.C. Deep Levels in n-Type 4H-Silicon Carbide Epitaxial Layers Investigated by Deep-Level Transient Spectroscopy and Isochronal Annealing Studies. IEEE Trans. Nucl. Sci. 2016, 63, 1083-1090. [CrossRef]

28. Nava, F.; Castaldini, A.; Cavallini, A.; Errani, P.; Cindro, V. Radiation Detection Properties of 4H-SiC Schottky Diodes Irradiated up to $10^{16} \mathrm{n} / \mathrm{cm}^{2}$ by $1 \mathrm{MeV}$ Neutrons. IEEE Trans. Nucl. Sci. 2006, 53, 2977-2982. [CrossRef]

29. Statham, P.J. Recent Developments in Instrumentation for X-ray Microanalysis. In Modern Developments and Applications in Microbeam Analysis; Love, G., Nicholson, W.A.P., Armigliato, A., Eds.; Springer: Wien, Austria; New York, NY, USA, 1998; pp. 1-9. (Suppl. 15), ISBN 978-3-211-83106-9. 
30. Ruddy, F.H.; Seidel, J.G.; Chen, H.; Dulloo, A.R.; Ryu, S.-H. High-Resolution Alpha-Particle Spectrometry Using 4H Silicon Carbide Semiconductor Detectors. IEEE Trans. Nucl. Sci. 2006, 53, 1713-1718. [CrossRef]

31. Bertuccio, G.; Caccia, S.; Nava, F.; Foti, G.; Puglisi, D.; Lanzieri, C.; Lavanga, S.; Abbondanza, G.; Crippa, D.; Preti, F. Ultra low noise epitaxial 4H-SiC X-ray detectors. Mat. Sci. Forum 2009, 615, 845-848. [CrossRef]

32. Bertuccio, G.; Puglisi, D.; Macera, D.; Di Liberto, R.; Lamborizio, M.; Mantovani, L. Silicon Carbide Detectors for in vivo Dosimetry. IEEE Trans. Nucl. Sci. 2014, 61, 961-965. [CrossRef]

(C) 2019 by the authors. Licensee MDPI, Basel, Switzerland. This article is an open access article distributed under the terms and conditions of the Creative Commons Attribution (CC BY) license (http://creativecommons.org/licenses/by/4.0/). 